\title{
Multiaxial Creep Testing Device for Nuclear Fuel Claddings
}

\author{
By Rami Pohja* \\ Pekka Moilanen ${ }^{+}$ \\ Juhani Rantala \\ Santtu Huotilainen" \\ Ville Tulkkif. \\ Ulla Ehrnsten ${ }^{\dagger}$ \\ Stefan Holmstrom *
}

\begin{abstract}
Mechanical properties and creep resistance are among the key issues in the selection of fuel cladding materials for future Gen-IV nuclear reactor applications. As for today's nuclear reactors, the Fukushima accident has increased the interest in accident-tolerant fuel cladding materials. Thin-walled fuel cladding tubes may exhibit anisotropic creep properties due to the manufacturing process. A newly developed Pneumatic Loading Apparatus (PLA) is capable of testing the multiaxial creep properties of thin-walled tubular specimens with internal pressure and an additional axial force. Because of its innovative design, the PLA is moveable and can be implemented in testing in extreme environments. The system functionality and accuracy was demonstrated by two biaxial creep tests performed on austenitic stainless steel DIN 1.4970 and E110 zirconium alloy specimens. Both materials showed anisotropic creep behavior and the PLA testing concept and equipment proved its capability to perform reliably and accurately biaxial creep testing of fuel cladding materials.
\end{abstract}

Keywords: Fuel cladding, Mechanical testing, Multiaxial creep, Nuclear reactor, Pneumatic Loading Apparatus.

\section{Introduction}

The development of fuel cladding materials has an important role in achieving high burn-up operation of future Gen-IV nuclear reactors, such as the supercritical pressurized water reactor (SCPWR), sodium-cooled fast reactor (SFR), and lead bismuth-cooled fast reactor (LFR) (Kimura et al., 2011). The Gen-IV reactor concepts to be implemented in the next 30 years set increased

\footnotetext{
* Research Scientist, VTT Technical Research Centre of Finland Ltd, Finland.

+ Senior Scientist, VTT Technical Research Centre of Finland Ltd, Finland.

Senior Scientist, VTT Technical Research Centre of Finland Ltd, Finland.

- Research Scientist, VTT Technical Research Centre of Finland Ltd, Finland.

* Senior Scientist, VTT Technical Research Centre of Finland Ltd, Finland.

${ }^{\dagger}$ Principal Scientist, VTT Technical Research Centre of Finland Ltd, Finland.

^Senior Scientist, Joint Research Centre - IET (European Commission), The Netherlands.
} 
demands for fuel cladding materials to withstand high-dose neutron irradiation environment at very high temperatures, which may under transient conditions temporarily rise up to $1000{ }^{\circ} \mathrm{C}$. Furthermore, corrosion resistance, stress corrosion cracking (SCC) resistance, mechanical properties and creep resistance are key issues in the selection of the candidate fuel cladding materials (Li et al., 2014). For Gen-IV concepts, such as Prototype Fast Breeder Reactor (PFBR), the internal pressure due to the accumulated fission gases released from the fuel matrix is assumed to form the most significant mechanical load on the fuel cladding tubes during the reactor operation. The fuel - clad interaction is assumed to be significant only during transient overpower incidents and the stresses outside the fuel cladding tube due to the flow of coolant are expected to be insignificant (Mathew et al., 2014).

As far as currently operating Gen-II and Gen-III reactors are concerned, the Fukushima accident has increased the interest in advanced materials for accident-tolerant fuel claddings that could withstand accident scenario environments, such as very high temperature exposure in steam, for several hours. Requirements as enforced by regulatory codes, such as RCC-MRx, ASME III NH, etc., and demands emerging from the aforementioned issues set high standards for the characterization and experimental testing practises of the fuel cladding materials. To fullfill these needs, innovative biaxial creep testing equipment suitable for fuel cladding material testing has been developed.

Studies of biaxial creep damage evaluation of materials are essential for designing practical applications as well as for characterizing the creep damage mechanisms under multiaxial stress states. An example of components subjected to biaxial creep damage are internally pressurized tubes, such as cladding tubes of nuclear fuel. From a continuum mechanics viewpoint, it is necessary to relate multiaxial and uniaxial stress states. The Von Mises relations provide a suitable method to evaluate the multiaxial stress state from a continuum and calculation standpoint. The Von Mises stress has traditionally been used as a stress parameter in assessments for the multiaxial creep damage and has been demonstrated as a suitable parameter to describe the creep deformation under multiaxial stress conditions (Blaine and Roberts, 1992). However, the applicability of Von Mises stress to the multiaxial creep damage assessment has not been thoroughly demonstrated due to two separate major creep damage processes. One is the damage occuring inside grains where the creep strain rate corresponds to the creep damage rate and occurs in short creep lifetime regimes. The other is the grain boundary damage caused by void formation which is observed in long creep lifetime regimes (Sakane and Tokura, 2002). Biaxial creep testing allows for characterizing both the hoop and axial creep components and anisotropic creep properties of thin-walled tubes.

Today, zirconium alloys are used as cladding tube materials for water cooled nuclear reactors. Zircaloys, which are hexagonal close packed materials, exhibit anisotropy in the creep properties, especially in cold-worked condition. Several studies indicate that the creep strength of such materials is different in the hoop and axial directions of the internally pressurized tube, because they 
form preferred orientations or texture during the manufacturing process (Yutaka, 1987; Murty and Charit, 2006; Li and Holt, 2007; Grosjean et al., 2009). Austenitic stainless steels are candidate materials for fuel claddings in e.g. Gen-IV Supercritical water (SCW) reactor concepts. These face centered cubic materials are not expected to show anisotropy in an annealed condition. However, the manufacturing process of thin-walled tubes made of austenitic stainless steel including cold working due to pilgering and drawing operations may introduce anisotrophy and texture even in these materials (Was et al., 2007). The Oxide dispersion strengthened (ODS) steels exhibit excellent high temperature creep resistance, improved corrosion resistance and improved resistance to radiation damage. If the challenges related to welding issues and the manufacturing process of ODS steels can be overcome, they form a promising group of alloys for nuclear fuel cladding applications in Gen-IV reactor concepts. However, the ODS steels can exhibit strongly directional microstructure leading to anisotropic mechanical properties due to fabrication process, especially when manufactured into thin-walled tubes (Dryepondt et al., 2014). For these reasons it is necessary to study the effect of the multiaxial stress state on the creep properties of current and candidate materials for nuclear fuel cladding tubes.

\section{Methodology and Equipment}

Conventional mechanical material testing systems produce the axial load on the specimen by using a moving pull rod. This feature, however, is disadvantageous for testing in liquid or pressurized environments since pressure boundary feed-throughs cause problems with leakage and friction forces that are difficult to fully control. In the Pneumatic Loading Apparatus (PLA) testing concept the axial load is produced utilizing pneumatic loading units called bellows. With bellows-based facility it is possible to design test set-ups with no moving parts over the pressure boundary, since the loading unit is connected to the control unit via pressure lines and electrical feedback connectors only. The system can therefore be used for testing small size specimens even in demanding and sensitive in-reactor testing environments for nuclear materials testing. The PLA concept has been successfully implemented for a multitude of material testing types, such as slow strain rate testing (SSRT), stress corrosion cracking (SCC) and creep-fatigue (CF) testing, in several demanding simulated and actual service environments including supercritical water (SCW), irradiative environments, hydrogen and high temperature corrosive pressurized gas environments (Pohja et al., 2013; Guimbal et al., 2009; Moilanen et al., 2013).

In the majority of experimental equipment intended for biaxial creep testing of tubes the axial and hoop stress is produced to the test specimen by the internal pressure only. In such applications the axial-hoop stress ratio is constant and cannot be manipulated by the testing facility. The PLA concept utilizes also the internal pressure for producing the axial and hoop stress to the 
test specimen, but the pneumatic loading units can additionally produce the axial load for the tubular test specimen either in push or pull direction, which enables testing with variable axial-hoop stress ratios. The functionality of the additional axial load system by bellows technology has already been demonstrated in several applications (Pohja et al., 2013; Guimbal et al., 2009; Moilanen et al., 2013).

The additional axial push or pull test load is applied to the test specimen by applying the internal pressure of up to 200 bar in the push or pull bellows, which is able to produce an axial force of up to $4 \mathrm{kN}$ to a thin-walled tubular specimen. The bellows internal pressure is produced by the pneumatic servo controlled pressure adjusting loops. These PLC (programmable logic control) loops can operate with air, helium and nitrogen gases depending on the testing environment. Internal pressure of the tubular test specimen is also PLC controlled by the high pressure control loop which is powered by Argon gas. The maximum pressure level for the high pressure loop for internal pressure of the tubular test specimen is 700 bar.

A comprehensive 3D model of the biaxial creep testing device was created using ironCAD ${ }^{\mathrm{TM}}$ software in order to ensure and optimize the structure and functionality of the loading frame already at the design stage. The loading frame of the biaxial creep testing device is shown in Figure 1. The loading frame, which is the supporting element for the test specimen, is equipped with two independent pneumatic loading units, bellows. Pneumatic loading units produce the axial load for the tubular test specimen either in a push or pull direction. Tubular specimen is fixed into loading frame by nuts. The upper end of the fixing point is fixed and the lower is moveable. The alignment of the moveable specimen end is done by thin metal sheets. The strain measurement system is based on the mechanical extensometers, which enable accurate strain measurement in axial and hoop directions from gauge length of the tubular specimen at elevated temperatures. The testing device is also designed for operation with a laser extensometer measurement system.

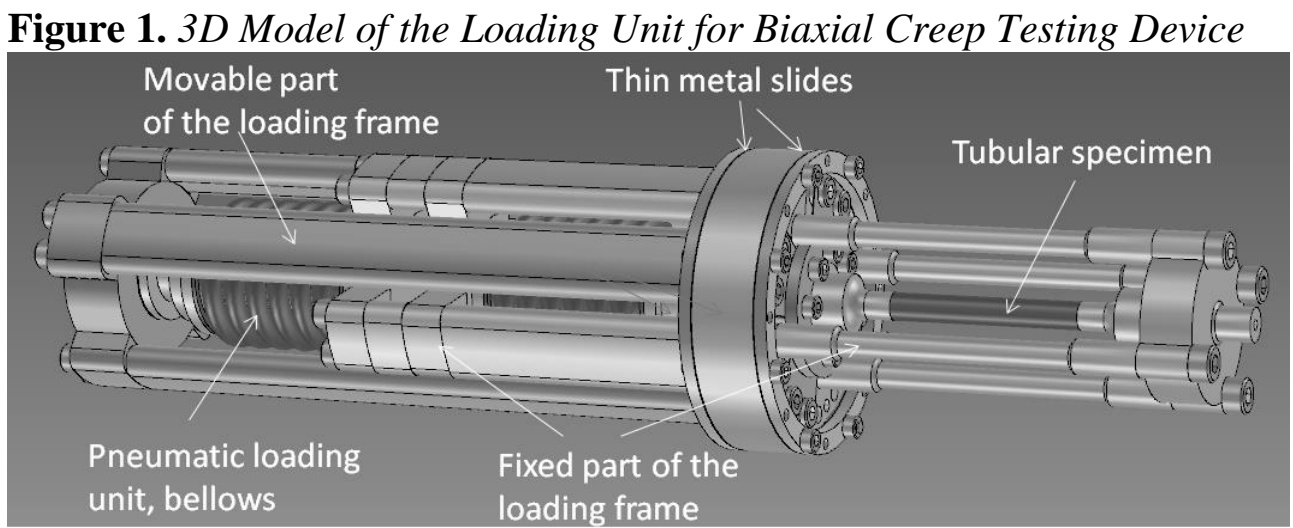

The load determination of the pneumatic loading unit is based on the special developed calibration method where the own stiffness of metal bellows and effective cross section are determined for the true load calculations. The load versus pressure calibration of the pneumatic loading unit has been 
performed in a gas environment using a tailor-made calibration frame. The calibration procedure consisted of two different tests. In the first calibration test, the pressure loss arising from the metal bellows own stiffness and internal parts, i.e. the friction fall of the pneumatic loading unit was determined over the working range. In the second calibration test, the interaction of pressure and load was determined by performing a constant load test over the working range. The own stiffness test was performed together with the loading frame and without the tubular specimen.

The biaxial material testing device has valuable features, in particular, its suitability for hot cell environment, where handling with the manipulators and the testing of different types of specimens with the same loading frame (tubular, bar and compact tension types) are basic requirements. A future objective is to use the equipment for pressurized tube creep tests at Gen-IV fuel cladding relevant conditions both in liquid bismuth environment (LBE) and in air.

\section{Results}

The system functionality and accuracy of the PLA was demonstrated by two biaxial creep tests performed on DIN 1.4970 austenitic stainless steel, also known as 15-15Ti steel, and E110 zirconium alloy specimens. The chemical compositions of tested materials are shown in Table 1.

Table 1. The Chemical Compositions of DIN 1.4970 and E110 Fuel Cladding Materials

\begin{tabular}{cccccccccccc}
\hline Element & $\mathrm{C}$ & $\mathrm{Ni}$ & $\mathrm{Cr}$ & $\mathrm{Mo}$ & $\mathrm{Ti}$ & $\mathrm{Si}$ & $\mathrm{Mn}$ & $\mathrm{Nb}$ & $\mathrm{Sn}$ & $\mathrm{Zr}$ & $\mathrm{Fe}$ \\
\hline DIN 1.4970 (wt.\%) & 0.096 & 15.05 & 15.06 & 1.21 & 0.44 & 0.57 & 1.86 & - & - & - & Bal. \\
\hline E110 (wt. \%) & - & 0.004 & 0.003 & - & - & - & - & 1.00 & 0.01 & Bal. & 0.014 \\
\hline
\end{tabular}

At initial stage, a reference test was performed for a tubular specimen manufactured of alloy DIN 1.4970, also known as 15-15Ti steel, fuel cladding tube with outer diameter of $6.55 \mathrm{~mm}$ and wall thickness of $0.45 \mathrm{~mm}$. The tubular specimen was tested in a $24 \%$ cold worked condition. Both hoop and axial strains of the test specimen were measured by high temperature extensometers. The gauge length in the axial direction was $25 \mathrm{~mm}$. Internal pressure of 600 bar was applied in the tubular test specimen using argon gas, additional axial push or pull test load by pneumatic bellows was not applied in this test. The test temperature was $550{ }^{\circ} \mathrm{C}$.

The stress values typically calculated for internally pressurized tubes are the axial stress, the mid-wall hoop stress and the Von Mises stress. The hoop and axial stresses are given in Equation (1) and (2), respectively;

$\sigma_{\text {el hoop }}=\frac{p}{y^{2}-1} \times\left(1+\left(\frac{D_{o}}{2} / r\right)^{2}\right)$

$\sigma_{\text {el axial }}=\frac{p}{y^{2}-1}+\frac{F_{a}}{A}$ 
where $p$ is internal pressure, $D_{o}$ is the outer diameter, $r$ is the radius and $y$ is the outer diameter $D_{o}$ divided by the inner diameter of specimen, $F_{a}$ is additional axial force and $A$ is the cross-sectional area of the specimen. The hoop and axial strains are given in Equation (3) and (4), respectively;

$\varepsilon_{\text {hoop }}=\frac{1}{E} \cdot\left(\sigma_{\text {el hoop }}-\sigma_{\text {elaxial }}{ }^{*} v\right)$

$\varepsilon_{\text {axial }}=\frac{1}{E} \cdot\left(\sigma_{\text {el axial }}-\sigma_{\text {el hoop }} \cdot v\right)$

where $E$ is the Young's modulus and $v$ is the Poisson's ratio.

The internal pressure of 600 bar was applied in the test specimen by linearly increasing the argon gas pressure during 100 seconds. The additional axial load was not applied in this test. Figure 2 shows the hoop and axial strains and stresses as a function of time during the pressurizing period. The measured hoop strain was slightly smaller than calculated whereas the measured axial strain was slightly higher than calculated. The stress-strain response was found to be nearly linear for both hoop and axial components, suggesting elastic behavior for the relatively small strains measured during the pressurizing period. The decrease in the measured axial strain after 80 seconds originates probably from a slip of the extensometer due to rapid strain change and thus does not indicate actual strain decrease. Furthermore, the temporary strain decrease after 80 seconds is very small, about $0.01 \%$ of the gauge length.

Figure 2. Hoop and Axial Stresses as well as the Measured and Calculated Hoop and Axial Strains during the Pressurizing Period for the 15-15Ti Alloy Test Specimen

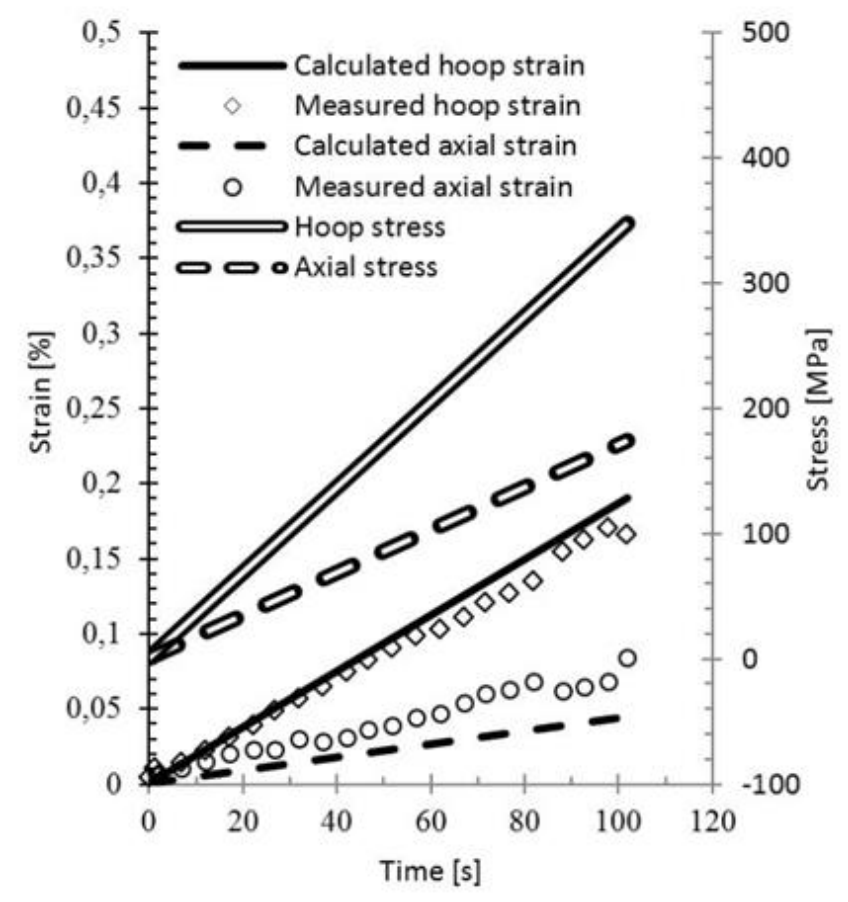

After the pressurizing stage the internal pressure of 600 bar was maintained for $560 \mathrm{~h}$ to investigate the hoop and axial strains and strain rates. 
During the steady state of the test, the temperature remained within $\pm 0.5{ }^{\circ} \mathrm{C}$ of the set value. The fluctuation for internal pressure was \pm 1 bar of the set value and for hoop and axial strains $\pm 0.005 \%$ of the gauge length.

For steady state creep stresses the ratio between hoop and axial stress is defined by Equation (5);

$\alpha=\frac{\sigma_{\text {cr hoop }}}{\sigma_{\text {craxial }}}$

where $\alpha$ is the stress ratio, $\sigma_{\text {cr hoop }}$ is the hoop creep stress and $\sigma_{\text {cr axial }}$ is the axial creep stress. For internally pressurized thin-walled tubes without additional axial load the stress ratio $\alpha$ equals 2 .

Figure 3 shows the hoop and axial strains as a function of time at the steady state of the test $\left(p=600 \mathrm{bar}, \sigma_{\text {cr hoop }}=377 \mathrm{MPa}, \sigma_{\text {cr } \text { axial }}=189 \mathrm{MPa}\right.$, $\alpha=2)$. Neither the hoop nor the axial strain curve did exhibit characteristics of the primary creep regime. Instead, the strain rate remained constant for both hoop and axial components throughout the steady state of the test. The solid line and dashed line in Figure 3 represent the trend lines for hoop and axial strain, respectively. The average strain rate was almost equal for hoop and axial components, exhibiting the strain rate values of $1.27 \cdot 10^{-4} \% / \mathrm{h}$ and $1.44 \cdot 10^{-4}$ $\% / \mathrm{h}$ for hoop and axial components, respectively.

Figure 3. Hoop and Axial strains as a Function of Time with Tube Internal Pressure of 600 bar at $550{ }^{\circ} \mathrm{C}$ for the 15-15Ti Alloy Test Specimen



For creep strain rate evaluation the Többe correlation was adopted to describe the correlation between effective stress and effective creep strain rate (Luzzi et al., 2014). The Többe correlation is based on the Nabarro-Herring equation, which is different from the typical Arrhenius equations used in the creep strain rate modelling (Többe, 1975). A modified version of Többe correlation is given by:

$\dot{\varepsilon}_{v}=A \cdot \exp \left(\frac{-Q}{R T}\right) \cdot \sinh \left(\frac{V^{*} \times \sigma_{V M}}{B \times R T}\right)$ 
where $\dot{\varepsilon_{v}}$ is creep strain rate, $Q$ is activation energy, $V^{*}$ is activation volume, $A$ and $B$ are constants and $\sigma_{V M}$ is the Von Mises effective stress;

$\sigma_{V M}=\sqrt{1 / 2\left[\left(\sigma_{\text {hoop }}-\sigma_{\text {axial }}\right)^{2}+{\sigma_{\text {hoop }}}^{2}+\sigma_{\text {axial }}{ }^{2}\right]}$

where $\sigma_{\text {hoop }}$ is hoop stress and $\sigma_{\text {axial }}$ is axial stress. The Von Mises effective strain can be calculated by:

$\varepsilon_{\text {ef }}=\sqrt{2} / 3\left[\left(\varepsilon_{\text {hoop }}-\varepsilon_{\text {axial }}\right)^{2}+\varepsilon_{\text {hoop }}{ }^{2}+\varepsilon_{\text {axial }}\right]^{20.5}$

with neglecting radial strain.

The calculated creep rates were compared to corresponding data from (Filacchioni et al., 1990) and (Gavoille et al., 2013) in Figure 4. The shown modified Többe curve is the best fit to the full temperature range of Gavoille data $\left(550-850{ }^{\circ} \mathrm{C}\right)$. Despite a higher axial strain rate than expected, in fact almost equal to the hoop strain rate, the effective strain rate was found to be in good accordance with the Gavoille data. The material tested by Filacchioni appeared to be more creep resistant compared to the Gavoille data and the result obtained in this study. The Filacchioni test specimens exhibited smaller effective strain rates with equal stress levels than the Gavoille test specimens. The difference in creep resistance may originate from material properties, for example from the amount of cold work. The amount of cold work was $24 \%$ for the 15-15Ti alloy specimen tested in this study, but the amount of cold work for the material used by Filacchioni and Gavoille was not presented in the references (Luzzi et al., 2014; Filacchioni et al., 1990; Gavoille et al., 2013).

Figure 4. The Effective Creep Strain Rate for 15-15Ti Steel Test Specimens and Többe Correlation Curve at $550{ }^{\circ} \mathrm{C}$ (Luzzi et al., 2014; Filacchioni et al., 1990; Gavoille et al., 2013)




At the second stage, a test with internal pressure and additional axial load was performed for a cold worked E110 specimen with outer diameter of 9.10 $\mathrm{mm}$ and a wall thickness of $0.70 \mathrm{~mm}$. The gauge length in the axial direction was $25 \mathrm{~mm}$. An internal pressure of $230 \mathrm{bar}$, which equals $126 \mathrm{MPa}$ mid-wall hoop stress, was applied in the specimen using argon gas. An additional axial pull load was applied to the specimen so that also the axial stress equaled 126 $\mathrm{MPa}$ in the test $(\alpha=1)$. The test temperature was $360{ }^{\circ} \mathrm{C}$ for the first 502 hours and $400{ }^{\circ} \mathrm{C}$ thereafter.

The internal pressure of 230 bar was applied in the specimen by linearly increasing the argon gas pressure during 900 seconds. After pressurizing the tube, the additional axial pull load was applied with decreasing stress rate during 400 seconds. Figure 5 shows the hoop and axial stresses as well as the calculated and measured axial and hoop strains as a function of time during the load apply period.

Figure 5. Hoop and Axial Stresses as well as the Measured and Calculated Hoop and Axial Strains during the Pressurizing Period for the Zirconium Alloy E110 Test Specimen

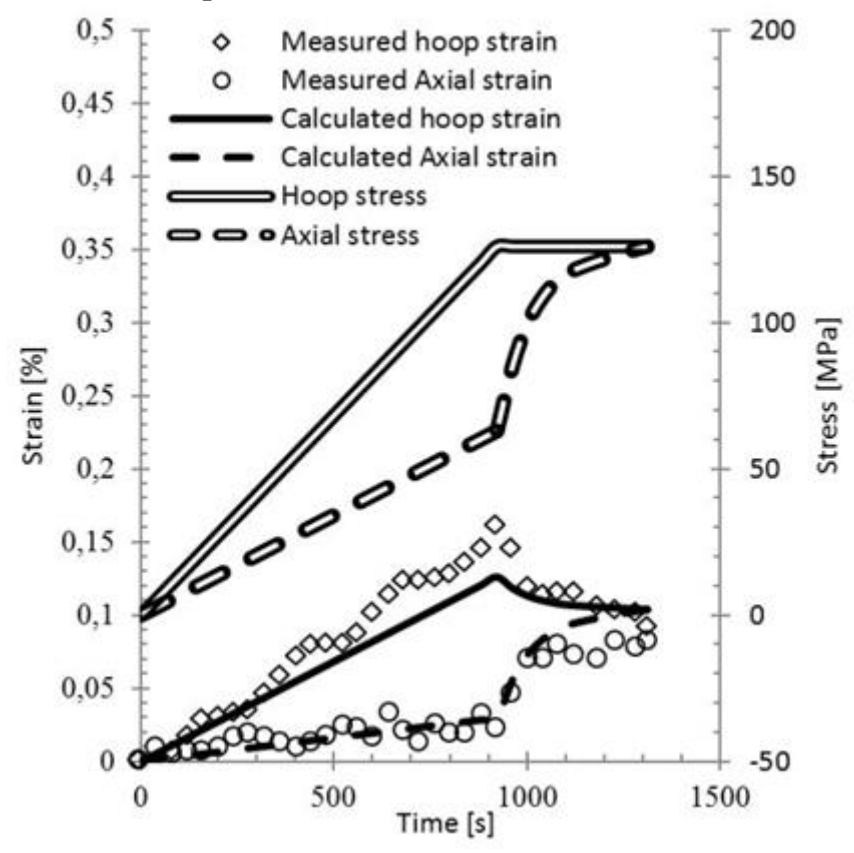

During the creep period of the test, the axial component exhibited a clear primary creep regime whereas the hoop strain even decreased during the first 100 hours of the test, as shown in Figure 6. However, after 400 hours the hoop creep strain rate was nearly equal to the axial creep strain rate. After 502 hours the test temperature was increased from $360{ }^{\circ} \mathrm{C}$ to $400{ }^{\circ} \mathrm{C}$ and the hoop and axial stresses were remained at $126 \mathrm{MPa}$, which led to an accelerated creep rate both for axial and hoop components. The axial component exhibited another primary creep regime for the increased temperature of $400{ }^{\circ} \mathrm{C}$, whereas the hoop creep strain rate was found to be significantly larger than the axial creep 
strain rate. The solid line and dashed line in Figure 6 represent the trend lines for hoop and axial strain, respectively. After 670 hours the test was terminated.

Figure 6. Hoop and Axial Strains as a Function of Time with 126 MPa Axial and Hoop Stress at $360{ }^{\circ} \mathrm{C}$ for the First 502 hours and $400{ }^{\circ} \mathrm{C}$ Thereafter for the Zirconium Alloy E110 Test Specimen

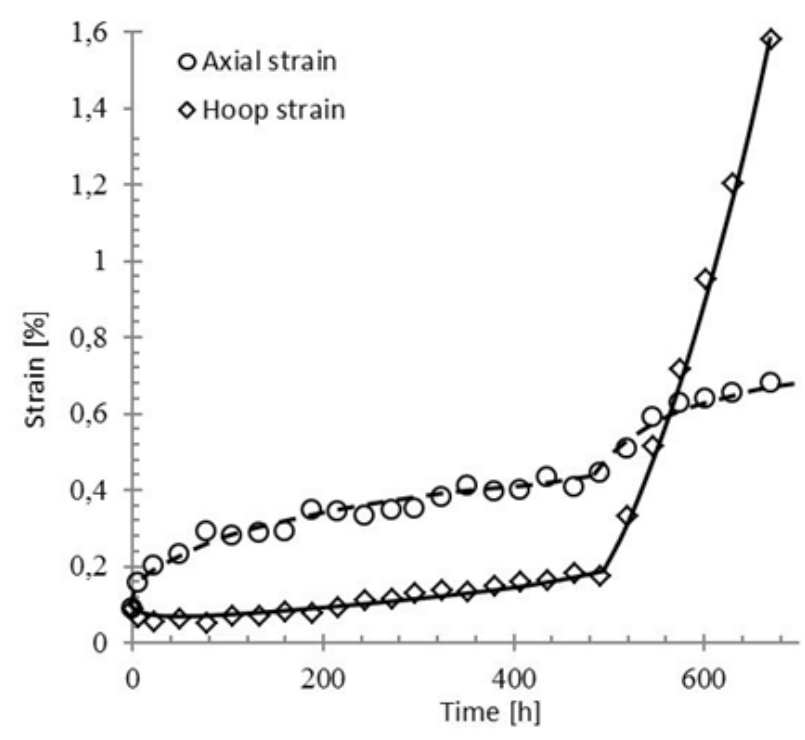

To explain in detail the anisotropic creep behavior of the tested E110 fuel cladding material further tests and microstructural evaluation are required. However, similar results were obtained by (Yan, 2005; Murty et al., 2006; Murty et al., 1994; Murty, 1999) indicating that the hoop creep strain rates of cold-worked zirconium alloys (Zircaloy-4 and Zirlo) were significantly higher than those of axial creep strain rates with $\alpha$ values of $0.67-1$. Figure 7 shows the creep curves of cold-worked Zirlo at $\alpha=1$ and $450{ }^{\circ} \mathrm{C}$ for different stresses in a test carried out by (Yan, 2005).

Figure 7. Creep Curves of Cold-worked Zirlo at $\alpha=1$ and $450{ }^{\circ} \mathrm{C}$ for Different Stresses (Yan, 2005)

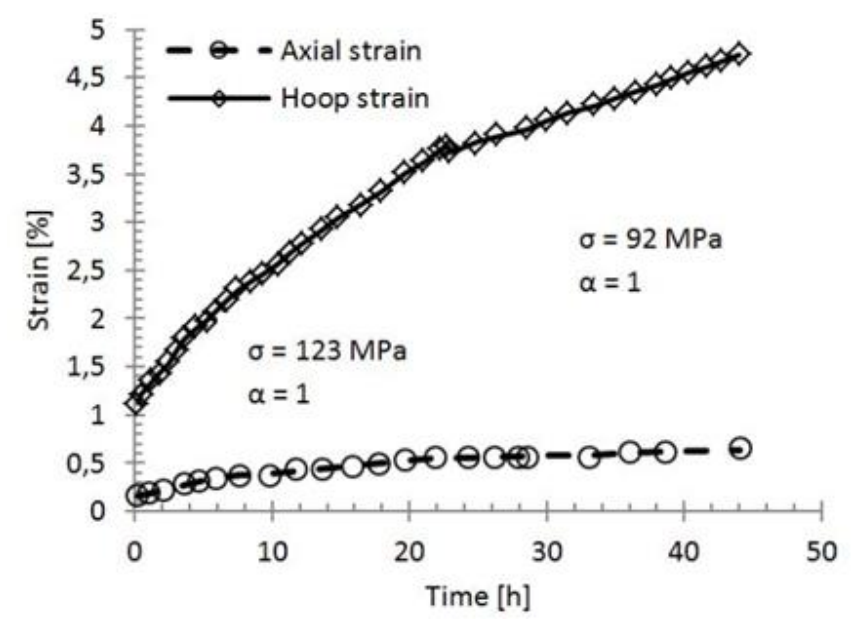


The performance of the equipment was accurate and reliable during the biaxial creep test for the E110 alloy. During the test, the temperature remained within $\pm 0.5^{\circ} \mathrm{C}$ of the set value. The fluctuation for internal pressure was \pm 1 bar of the set value and $\pm 0.005 \%$ for hoop and $\pm 0.01 \%$ for axial strain.

\section{Discussion}

A pneumatic loading apparatus for biaxial creep testing has been designed and applied for characterizing the multiaxial creep properties of nuclear fuel claddings. A reference test for $15-15 \mathrm{Ti}$ steel was carried out at $550{ }^{\circ} \mathrm{C}$ using an internal tube pressure of 600 bar without an additional axial load. In the second test the internal pressure and additional axial load was applied to an E110 zirconium alloy specimen with $\alpha$ ratio of 1 . The overall accuracy of temperature, internal pressure and additional axial load control system as well as the strain measurement system was found to be at a sufficient level. A major advantage of the PLA concept is the fact that the actual loading unit is compact and moveable and it is connected to the control unit via pressure lines and electrical feedback connectors only, which can be protected from extreme environments. This is seen to enable the use of the equipment in the future for pressurized tube creep tests at Gen-IV fuel cladding relevant conditions in LBE environments and in irradiation environments in the hot cell.

For the tested 15-15Ti steel specimen the axial strain exhibited larger values than expected for isotropic material, and any characteristics of primary creep regime could not be obtained from creep curves for both hoop and axial strains during the test. Furthermore, the strain rate for the axial component was almost equal to the strain rate of the hoop component, although the axial stress was significantly lower than the hoop stress $(\alpha=2)$.

Accordingly, in a study carried out by (Mathew et al., 2014) relatively high axial strain rates were obtained in the biaxial creep tests for $\mathrm{Fe}-14 \mathrm{Cr}-$ $15 \mathrm{Ni}-\mathrm{Ti}$ modified austenitic stainless steel in $20 \%$ cold worked condition. However, although unexpectedly high, in that study the hoop strain rates were found to be about one order of magnitude higher than the axial strain rates for a given gas pressure. (Mathew et al., 2014) performed Orientation Imaging Microscopy (OIM) followed by Electron Back Scatter Diffraction (EBSD) analysis for the material in $20 \%$ cold worked condition and suggested that rather high axial strain rates observed in the tests originate from anisotropy of the creep deformation due to thermomechanical processing.

The 15-15Ti material tested in this study was in $24 \%$ cold worked condition, which may have introduced preferred orientations of the grains or textures, leading to high strain rates in the axial direction. However, conclusions on the subject cannot be made at this point, since the microstructural evaluation is yet to be performed for the tested material. As for effective strain rate, the test result was in rather good accordance with Gavoille data and Többe correlation curve at $550{ }^{\circ} \mathrm{C}$ as shown in Figure 4. (Mathew et al., 2014) observed that steady state hoop rates from biaxial loading and steady 
state creep rates from uniaxial loading were comparable at $700{ }^{\circ} \mathrm{C}$. For the present study, uniaxial creep data for $15-15 \mathrm{Ti}$ at $550{ }^{\circ} \mathrm{C}$ was unfortunately unavailable for the comparison.

Creep rates in zirconium alloys are different in different crystallographic or macroscopic directions due to its well-known anisotropic HCP crystal structure and the associated texture formed during component fabrication, such as cold working. Consequently, anisotropic creep properties, where the hoop creep strain rates are higher than the axial creep strain rates with $\alpha=1$ have been reported in the literature (Yan, 2005; Murty et al., 2006; Murty et al., 1994; Murty, 1999). According to (Murty et al., 2006; Murty et al., 1994; Murty, 1999) the higher hoop creep strain rates compared to axial creep rates originate from anisotropic microstructural properties of cold-worked zirconium alloys and stress enhancement occurring in the hoop direction during grain boundary sliding in creep deformation. This could explain the significantly high hoop creep strain rate of the E110 specimen at $400{ }^{\circ} \mathrm{C}$ observed in this study. A near future objective is to perform microstructural characterization for the tested material to deepen the understanding of the anisotropic creep behavior of the material in question.

Another future objective is to launch test programs for zirconium alloy cladding materials and Gen-IV fuel cladding candidate materials, such as 15$15 \mathrm{Ti}$ and ferritic ODS alloys. With additional axial load the ratio of axial to hoop stress can be varied. Balanced biaxial creep tests with equal hoop and axial stresses $(\alpha=1)$ are considered to be of particular significance since the ratio of the creep strain in the hoop and axial directions provides an indication of the creep anisotropy of the material.

\section{Conclusions}

A biaxial creep test has been performed for a tubular DIN 1.4970 alloy specimen with internal pressure and E110 zirconium alloy specimen with internal pressure and additional axial load in order to demonstrate the functionality and accuracy of pneumatic loading apparatus for biaxial creep testing. Both materials exhibited anisotropic creep behavior in the tests. The performance and accuracy of the main control and measurement systems of the biaxial creep testing device were found to be at a reliable and accurate level. The PLA testing concept and equipment proved its capability to perform reliably and accurately bi-axial creep testing of fuel cladding materials with different axial-hoop stress ratios and with temperature and stress transients during tests.

\section{Acknowledgements}

Our thanks to the Academy of Finland project IDEA (Interactive Modelling of Fuel Cladding Degradation Mechanisms) as well as the 
MATTER (Materias testing and rules, Project no: 269706 - FP7-Fission-2010) and TASTE (Testing and assessment methodologies for material characterization of thin-walled cladding tubes) projects under the umbrella of EERA Joint Program on Nuclear Materials for support.

\section{References}

Blaine, W. and Roberts, W. 1992. Influence of Multiaxial Stressing on Creep and Creep Rupture. In ASM Handbook - Volume 8: Mechanical Testing, J. Davis and S. Refsnes Eds. American Society of Metals, ASM. ISBN 0-87170-007-7.

Dryepondt, S., Unocic, K., Hoelzer, D. and Pint, B. 2014. Advanced ODS FeCrAl alloys for accident-tolerant fuel cladding. Oak Ridge National Laboratory Report ORNL/TM-2014/380, Oak Ridge, Tennessee.

Filacchioni, G., De Angelis, U., Ferrara, D. and Pilloni, L. 1990. Mechanical and structural behaviour of the second double stabilized stainless steels generation. International Conference on Fast Reactor Core and Fuel Structural Behaviour. (London, UK, June 4-6, 1990).

Gavoille, P., Courcelle, A., Seran, J. L., Averty, X., Bourdiliau, B., Provitina, O., Garat, V. and Verwaerde, D. 2013. Mechanical properties of cladding and wrapper materials for the ASTRID Fast-Reactor Project. IAEA International Conference on Fast Reactors and Related Fuel Cycles: Safe Technologies and Sustainable Scenarios (FR13). (Paris, France, March 3-4, 2013).

Grosjean, C., Poquillon, D., Salabura, J-C. and Cloué, J-M. 2009. Experimental creep behaviour determination of cladding tube materials under multiaxial loadings. Mater. Sci. Eng. A. 510-511, 15 (Jun. 2009), 332-336.

Guimbal, P., Auclair, M., Carassou, S., Moilanen, P., Tähtinen, S. and Villard, J-F. 2009. MELODIE, an advanced device for study of the irradiation creep of LWR cladding with online biaxial control of stress and strain. 12th Conference IGORR International Group on Research Reactors, (Beijing China, October 2830, 2009).

Kimura, A., Kasada, R., Iwata, N., Kishimoto, H., Zhang, C. H., Isselin, J., Dou, P., Lee, J. H., Muthukumar, N., Okuda, T., Inoue, M., Ukai, S., Ohnuki, S., Fujisawa, T. and Abe, T. F. 2011. Development of Al added high-Cr ODS steels for fuel cladding of next generation nuclear systems. J. Nucl. Mater. 417, 1-3 (Oct. 2011), 176-179.

Li. W. and Holt, R. 2007. Effect of Texture on Anisotropic Creep of Pressurized Zr2.5Nb Tubes. Mater. Sci. Forum. 539-543 (Mar. 2007), 3353-3358.

Li, J., Zheng, W., Penttilä, S., Liu, P., Wooc, O. T. and Guzonas, D. 2014. Microstructure stability of candidate stainless steels for Gen-IV SCWR fuel cladding application. J. Nucl. Mater. 454, 1-3 (Nov. 2014), 7-11.

Luzzi, K., Cammi, A., Di Marcello, V., Lorenzi, S., Pizzocri, D. and Van Uffelen, P. 2014. Application of the TRANSURANUS code for the fuel pin design process of the ALFRED reactor. Nucl. Eng. Des. 277, 1 (Oct. 2014), 173-187.

Mathew, M. D., Ravi, S., Vijayanand, V. D., Latha, S., Dasgupta, A. and Laha, K. 2014. Biaxial creep deformation behavior of $\mathrm{Fe}-14 \mathrm{Cr}-15 \mathrm{Ni}-\mathrm{Ti}$ modified austenitic stainless steel fuel cladding tube for sodium cooled fast reactor. $\mathrm{Nucl}$. Eng. Des. 275, (Aug. 2014), 17-22. 
Moilanen, P., Holmström, S., Novotny, R., Hähner, P. and Nilsson, K-F. 2013. New applications of pneumatically powered testing equipment for extreme environments. In Baltica IX - International Conference on Life Management and Maintenance for Power Plants, VTT Technology 106, P. Auerkari, J. Veivo, Eds., VTT, Espoo, Finland, 2013, 318-336.

Murty, K. L. 1999. Creep Studies for Zircaloy Life Prediction in Water Reactors. JOM. 51, 10 (Oct. 1999), 32-39.

Murty, K. and Charit, I. 2006. Texture development and anisotropic deformation of zircaloys. Prog. Nucl. Energy. 48, 4 (May 2006), 325-359.

Murty, K. L., Tanikella, B. V. and Earthman, J. C. 1994. Effect of Grain Shape and Texture on Equi-Biaxial Creep of Stress Relieved and Recrystallized Zircaloy-4. Acta Metall. Mater. 42, 11 (Nov. 1994), 3653-3661.

Pohja, R., Nurmela, A., Moilanen, P. and Holmström, S. 2013. Multifunctional high precision pneumatic loading system (HIPS) for creep-fatigue testing. Procedia Engineering. 55, 6th International Conference on Creep, Fatigue and CreepFatigue Interaction (2013), 573-577.

Sakane, M. and Tokura, H. 2002. Experimental Study of Biaxial Creep Damage for Type 304 Stainless Steel. Int. J. Damage Mech. 11, 3 (Jul. 2002), 247-262.

Többe, H. 1975. Das Brennstabrechenprogramm IAMBUS zur Auslegung von Schellbrüter-Brennstäben [The Fuel Rod Calculation program IAMBUS for the Design of Fast Breeder Fuel Rods]. Technical Report ITB 75.65, Interatom, Bensberg, 1975, 60-74.

Was, G. S., Ampornrat, P., Gupta, G., Teysseyre, S., West, E.A., Allen, T. R., Sridharan, K., Tan, L., Chen, Y., Ren, X. and Pister, C. 2007. Corrosion and stress corrosion cracking in supercritical water. J. Nucl. Mater. 371, 1-3 (Sep. 2007), 176-201.

Yan, J. 2005. Crystallographic Texture and Creep Anisotropy in Cold Worked and Recrystallized Zirlo. Doctoral Thesis. Order Number: 27695-7909. Department of Nuclear Engineering, North Carolina State University, Raleigh, NC.

Yutaka, M. 1987. Thermal Creep of Zircaloy4 Cladding under Internal Pressure. $J$. Nucl. Sci. Technol. 24, 2 (Feb. 1987), 111-119. 